\title{
GLOBALIZAÇÃo ECONÔMICA, DESMONTE DO ESTADO SOCIAL E DÉFICIT POLÍTICO TRANSNACIONAL: UMA ANÁLISE CRÍTICA A PARTIR DE JÜRGEN HABERMAS ${ }^{1}$
}

\author{
Jorge Adriano Lubenow ${ }^{2}$
}

Resumo: $\mathrm{O}$ artigo trata da análise crítica de Jürgen Habermas a respeito das consequências do modelo neoliberal de integração global via mercado, em especial o desequilíbrio entre política e mercado, o fim do compromisso com o Estado social e o déficit democrático no nível transnacional. Para o filósofo alemão, a concepção neoliberal de sociedade desestatizada do capitalismo global atinge o nexo entre Estado nacional, democracia e justiça social, marginalizando o Estado e a política, em favor da privatizaçáo dos serviços públicos e sendo insensível às questôes de justiça social, aos custos sociais do crescente aumento da pobreza, desigualdade e exclusão social, mesmo em países abastados da Europa e América do Norte. Ao deslocar o fiador da integração social para além das fronteiras nacionais, o capitalismo global foge ao controle estatal e esvazia o poder dos Estados nacionais, em termos de substância democrática e de política social, e gera um déficit de legitimação, ao transferir competências nacionais para agências ou organismos transnacionais, cuja legitimação não deriva da sociedade civil ou de uma esfera pública politicamente constituída. Em contrapartida, Habermas defende um poder democrático capaz de domesticar politicamente o mercado globalizado, reconstruir a democracia estatal-social num nível transnacional, em vista de uma ordem socialmente mais equilibrada, e compensar o déficit social e de legitimação democrática, no âmbito transnacional. Depois de recapitular alguns problemas que se solucionaram nas formas de Estado nacional, o artigo

${ }^{1}$ Este artigo resulta de uma pesquisa de pós-doutorado financiada pela CAPES sobre democracia transnacional em Jürgen Habermas, realizada junto à Europa-Universität Flensburg/Alemanha, no semestre de inverno 2014-2015, sob a orientação do Prof. Dr. Hauke Brunkhorst. Uma versão preliminar foi apresentada na disciplina "Transnational Democracy Europe and beyond", coordenada pelo mesmo professor, e também na conferência de encerramento da I Jornada do NEFIPE - Núcleo de Estudos em Filosofia Política e Ética da UFPE, em Recife, dia 23/11/2016. Agradeço aos colegas do NEFIPE da UFPE e do PPG-Filosofia da UFPB pelos comentários e observaçōes críticas. Sobre o impacto da globalização econômica na integração política europeia, o novo perfil econômico-liberal da Europa e o déficit democrático das instituiçóes políticas da Uniāo Europeia, ver: LUBENOW $(2015,2016,2017)$.

2 Doutor em Filosofia pela UNICAMP. Pós-Doutor em Filosofia pela Europa-Universität Flensburg/ Alemanha (2015) e pelo CNPq/FAFEPI (2010). Professor Associado I do DFE e Professor permanente do Programa de Pós-Graduação em Filosofia da Universidade Federal da Paraíba (UFPB). Coordenador do Centro de Pesquisas em Democracia da UFPB e do Grupo de Pesquisa em Democracia (CNPq/UFPB), João Pessoa, PB - Brasil. (D) http://orcid.org/0000-0001-6043-4538 E-mail: jlubenow@hotmail.com

http://doi.org/10.1590/0101-3173.2020.v43n2.06.p99

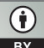

This is an open-access article distributed under the terms of the Creative Commons Attribution License. 
descreve como a globalização econômica afeta a soberania cultural, econômica, administrativa e jurídica, política, social e trabalhista dos Estados nacionais (1), e quais as possibilidades de reenquadrar politicamente os mercados, estendendo a democracia estatal para além das fronteiras nacionais (2). Com isso, quer-se mostrar que a obra de Habermas não é cega para a relação democracia-capitalismo, para os efeitos colaterais da "colonização da política pela economia", para a influência corrosiva da economia capitalista na despolitização da esfera pública e da política.

Palavras-Chave: Jürgen Habermas. Globalização econômica. Democracia transnacional. Déficit de legitimação. Estado social.

Não se pode ter legitimidade democrática sem justiça social. (HABERMAS, 1998, p. 8)

\section{INTRODUÇÃo}

O Estado nacional configurou-se como uma constelação histórica de integração social capaz de resolver problemas que não podiam mais ser resolvidos no âmbito local/comunidades, criando uma nova forma de solidariedade ainda mais abstrata entre estranhos nas formas de Estado nacional, criando um nexo entre Estado nacional e identidade/consciência nacional, soberania, nação, território, economia, finanças, fiscal, administrativa, jurídica, política, social, entre outras (HABERMAS, 1992, 1996, 1998).

Historicamente, o Estado nacional se definiu por língua, hábito, tradição em comum, fronteira e domínio estatal territorial e social. A formação da identidade nacional se caracterizou pela superação dos vínculos regionais, particularistas; um processo difícil de superação da lealdade para com a aldeia, a família, a regiáo e a dinastia, para uma compreensão mais universalista e abstrata de integração social. A consciência de unidade na multiplicidade foi assumida, depois da religião, pela nação e pela consciência natural de pertença. A formação da identidade nacional configurou-se na passagem de uma identidade presa à localidade, família, tradiçóes regionais, para uma unidade imaginária abstrata mais ampla, uma nova forma de identidade coletiva. Essa construção simbólica foi mobilizada em forma de integração cultural e preenchida pela ideia de nação de cidadáos de um Estado. Essa nova consciência nacional foi abastecida pelo substrato cultural em vista de uma solidariedade cívica. Tratou-se de uma nova maneira de solidariedade, mais abstrata, na qual os membros de uma nação se sentiam corresponsáveis, mesmo estranhos entre si (vejam-se os casos do serviço militar obrigatório, o pagamento de impostos etc.). 
No sentido político, o Estado nacional constituiu um novo modo secularizado de legitimação, possibilitando uma nova espécie de integração social via consciência nacional, uma solidariedade abstrata mediada política e juridicamente. O Estado nacional foi o lugar no qual se articulou a ideia republicana de ação consciente e efetiva de uma sociedade sobre si mesma. No entanto, para Habermas, essa forma de institucionalização baseada no Estado nacional se encontra cada vez mais ameaçada pela globalização econômica, cuja dinâmica ameaça não só a soberania territorial, a efetividade do Estado regulador e a identidade coletiva, mas também as condições de funcionamento e de legitimação do processo democrático, em sua forma nacional. Isso impóe limites e desafios ao Estado nacional, que ultrapassam a capacidade de ação política e corroem a soberania interna dos Estados nacionais, afetando a soberania e a nacionalidade. Nesse sentido, estaríamos enfrentando um desafio similar ao da formação dos estados nacionais:

A seu tempo, o Estado nacional foi uma resposta convincente ao desafio histórico de encontrar um equivalente funcional às formas de integração social tidas na época como em processo de dissolução. Hoje estamos novamente diante de um desafio análogo. A globalização em trânsito e da comunicação, da produção econômica e de seu financiamento, da transferência de tecnologia e poderio bélico, em especial dos riscos militares e ecológicos, tudo isso nos coloca em face de problemas que não se podem mais resolver no âmbito dos Estados nacionais, nem pela via habitual do acordo entre Estados soberanos. Salvo melhor juízo, tudo indica que continuará avançando o esvaziamento da soberania dos Estados nacionais. (HABERMAS, 1996, p. 129-130).

\section{Impactos da globalizaÇáo ECONÔMICA SOBRE a SOBERANIA DOS ESTADOS E DEMOCRACIAS NACIONAIS}

Quais os impactos da globalização econômica sobre o Estado nacional? Como a globalizaçáo econômica impacta o nexo entre Estado nacional e identidade nacional? Como a globalização afeta a soberania econômica, política, social, fiscal, territorial, de mercado de trabalho, entre outras?

A "globalização" é uma modificação estrutural do sistema econômico mundial para além das fronteiras dos Estados nacionais reguladores, transformando e diluindo as tênues fronteiras que separam a economia, a administração, a sociedade e a cultura, e engendrando processos "pós-nacionais" 
que fogem ao controle estatal. A "constelação pós-nacional”3 significa o esvaziamento do poder do Estado nacional. Além do enfraquecimento, em termos de soberania (econômica, financeira, fiscal, administrativa, jurídica...), o Estado nacional perde em termos de autonomia e competência de ação (capacidade de controle), em substância democrática (déficit de legitimação) e de política social (fornecer serviços de modo eficaz). A perda da autonomia se revela na incapacidade do Estado nacional em proteger os cidadáos contra os efeitos de decisóes externas, fora de suas fronteiras, mas que impactam, de modo decisivo, nos âmbitos internos de ação (problemas ecológicos, crime organizado, tráfico de armas, epidemias, segurança tecnológica, entre outros).

a) Soberania cultural. Como a globalização econômica influencia o nexo entre Estado nacional e cultura/identidade nacional? Impacto cultural.

Para Habermas, a globalização econômica engendrou processos de diferenciação cultural da sociedade (pluralidade cultural) pós-nacionais que afetam a função integrativa cultural do Estado nacional (ideia de povo/nação) e corroem a identidade coletiva nacional. Com isso, provoca uma dinâmica dupla na consciência nacional, a qual oscila entre fechamento e abertura; vejamse os sintomas da fragmentaçáo do substrato cultural nacional manifestada na perda da solidariedade cívica e que se intensificam interna e externamente. Internamente, no estabelecimento de políticas mais rígidas de imigração e nas reaçóes etnocêntricas ao que é estrangeiro; externamente, a capacidade de coesão cultural é pressionada a se abrir internamente para a pluralidade dos modos de vida, e que decorre do consumo, comunicaçáo e turismo de massa, os quais difundem uma espécie padronizada de cultura (geralmente e preponderantemente norte-americana). Escreve Habermas (1996, p. 141):

A seu tempo, o Estado nacional proporcionou um contexto de comunicação política em que foi possível aparar os impulsos abstrativos da modernização social, tomar uma populaçáo privada do seu contexto de vida que ela havia herdado da tradição e reacomodá-la no encadeamento de um mundo vital ampliado e racionalizado, também pela via da consciência nacional. Foilhe possível cumprir essa função integrativa assim que o status jurídico do cidadáo vinculou-se ao fato de se pertencer culturalmente à nação [...]. Porém, em sociedades pluralistas, convivemos hoje com evidências cotidianas que se distanciam cada vez mais do modelar Estado nacional com uma populaçáo culturalmente homogênea.

\footnotetext{
${ }^{3}$ Embora essa discussão sobre o Estado social transnacional apareça nas várias obras aqui citadas, ela é a questão central de HABERMAS (1998).
} 
A diferenciação e a multiplicidade das formas culturais de vida, grupos étnicos, diferentes confissóes religiosas e imagens de mundo impóem o desafio de pensar o que pode conferir unidade a essa cultura política, nessa multiplicidade de subculturas. Trata-se aqui da existência de uma lacuna de integração social.

Para Habermas, o papel de fiador numa sociedade pluralista, no que diz respeito à cultura e às visões de mundo, não pode ser delegado a um substrato aparentemente natural de um povo pretensamente homogêneo, mas, sim, deve ser transferido para o plano da formação política da vontade e da comunicação pública. Nesse caso, o processo democrático deve se prestar como fiador da integração social cada vez mais diferenciada, desacoplando cada vez mais o plano da cultura política partilhada do plano das subculturas e suas identidades, cunhadas de maneira anterior à política; algo como um "patriotismo constitucional" (Verfassungspatriotismus) poderia ocupar, como "liga/coesão" (Zusammenhalt), o lugar do nacionalismo original (HABERMAS, 1996). No entanto, a tendência de uma autocompreensão "pós-nacional" da coletividade política tornou-se um problema tanto para países, como os Estados Unidos, quanto para a maioria dos países da Europa Ocidental; vejam-se os casos de fundamentalismo, terrorismo, nacionalismo, etnocentrismo, imigraçáo, hostilidade contra estrangeiros.

Além disso, o desafio do multiculturalismo alerta para uma nova forma de solidariedade entre cidadãos, num nível mais abstrato de um universalismo mais sensível às diferenças. Em contrapartida, é preciso articular, na sociedade civil e nas esferas públicas políticas dos Estados nacionais, a modificação da consciência dos cidadãos em vista de uma consciência de solidariedade cosmopolita, no sentido de se compreenderem como fazendo parte cada vez mais de uma comunidade mundial. Todavia, Habermas (1998) descrê na capacidade das elites governantes nacionais de articularem uma consciência de pertença ampliada e situa esse encadeamento no seio dos movimentos sociais e das organizaçôes não-governamentais. Apesar de alguns exemplos de mudança de mentalidade (mentalidade pacifista, ecológica), a despeito de não serem de todo ineficazes, não têm força vinculante suficiente; uma solidariedade cosmopolita até o momento inexiste. Mas isso não significa que não seja possível continuar aquela histórica virada abstrata da consciência local/regional em nacional democrática para uma passagem dessa a uma nova forma, também abstrata, de consciência cosmopolita. 
b) Soberania econômica/financeira. Como a globalização influencia o nexo entre Estado nacional e economia? Impacto econômico.

A relação entre sistema estatal e dinâmica econômica teve papel importante na fixação do Estado nacional. Trata-se da relação complementar típica entre Estado e economia. Contudo, a globalização altera a anterior relação recíproca entre Estado e economia, visível de modo particular no caso da crescente desnacionalização da produçâo econômica e consequente desregulação dos mercados.

A desnacionalização da economia implica que as relações produtivas globalmente ligadas em rede não podem ser mais influenciadas por meios políticos e, por conseguinte, a "política" perde, de modo progressivo, o domínio sobre as condiçôes de produção das quais provêm as estatais receitas tributáveis. Ao ter cada vez menos influência sobre as empresas, os governos se defrontam com o dilema: protecionismo e formação de cartéis nacionais ou desregulação sociopolítica. Abrir mão do controle político (ver, abaixo, "d") significaria aceitar as consequências sociais do desmonte do Estado social (ver, abaixo, "e" e "f"), em vista da concorrência no mercado internacional.

O que fazer? Segundo Habermas, assim como o Estado intervencionista regulava a economia nacional, da mesma forma é preciso haver a construção de instituiçóes políticas supranacionais capazes de regular a economia transnacional. A política deve acompanhar o mercado, no âmbito transnacional. Nesse sentido, a formação de blocos econômicos regionais (por exemplo: União Europeia, MERCOSUL, NAFTA, ALCA, ASEAN) ${ }^{4}$ é uma tentativa de organizar e fortalecer agentes regionais aptos a atuar no plano global. No entanto, para Habermas, a integração com ênfase econômica não se faz sem prejuízo político, uma vez que os Estados nacionais abrem máo tanto da soberania financeira como da soberania política, em favor de uma união primordialmente monetária, a qual acompanha o mercado na dinâmica de valorização do capital isenta de quaisquer liames políticos de formação democrática. O exemplo mais evidente é o da União Europeia, que se organizou em forma de um mercado comum europeu (ou Comunidade Econômica Europeia), mas encontra resistência de seus países-membros para a organização de um ordenamento político regional em vista de uma “Constituição Europeia”. Escreve Habermas (1996, p. 149):

${ }^{4}$ UNIÃO EUROPEIA: Comunidade Econômica Europeia; MERCOSUL: Mercado Comum do Sul; NAFTA: Tratado Norte-Americano de Livre Comércio; ALCA: Área de Livre Comércio das Américas; ASEAN: Associação das Naçōes do Sudeste Asiático. 
Desde o Tratado de Maastricht, cresce nos Estados-membros a resistência à expansão vertical de uma União Europeia que dessa forma assumiria ela mesma os traços essenciais de um Estado e mediaria as relaçóes entre seus membros, todos eles Estados nacionais. Sob a consciência das conquistas históricas, o Estado nacional assume uma postura rígida ao levar em conta a sua identidade, já que se vê atropelado e enfraquecido pelos processos de globalização. Hoje como ontem, a política de cunho estatal-nacional ainda se limita a adequar a sociedade, de forma o mais indulgente possível, aos imperativos sistêmicos e efeitos secundários de uma dinâmica econômica global que se mostra amplamente desvinculada das condiçóes políticas circunstantes.

As tentativas de constituição de alianças políticas mais amplas, a partir da formação de blocos econômicos regionais, infelizmente não levaram à modificação do modus operandi econômico, em função da influência política. Diante das dificuldades de uma articulação política pós-nacional, capaz de garantir uma domesticação das consequências sociais do capitalismo globalizado, falta nesse nível um arranjo político organizado a fim de coordenar e regular o trânsito comercial globalizado dentro de indicadores sociais aceitáveis. Além disso, apesar da teia de relaçóes estabelecida pela Organização das Naçóes Unidas, Habermas também descrê na capacidade da ONU de coordenar afirmativamente e preencher aquela função reguladora. Também nas ciências sociais não encontraríamos nem sequer um projeto de uma política capaz de abranger os mercados (HABERMAS, (1998). ${ }^{5}$

c) Soberania administrativa e jurídica. Como a globalização influencia o nexo entre Estado nacional e efetividade administrativa e segurança jurídica? Impacto administrativo e jurídico.

A efetividade administrativa reguladora e a segurança jurídica do Estado nacional são afetadas por novas ameaças que ultrapassam as fronteiras nacionais, tais como problemas ecológicos (problemas atômicos ou buracos na camada de ozônio), criminalidade organizada, tráfico de drogas e de armas, ou mobilidade acelerada de capitais (que ameaçam emigrar, em virtude da taxação dos lucros).

\footnotetext{
${ }^{5}$ Sobre as críticas à ONU, ver: Habermas (2004, cap. 7).
} 
d) Soberania política. Como a globalização influencia o nexo entre Estado nacional e democracia? Em que sentido a globalização econômica poderia afetar o funcionamento das democracias nacionais? Impacto político.

Embora nem todos os Estados nacionais sejam considerados "democráticos", em muitos lugares apenas com a constituição de Estados nacionais (e suas diferentes matizes constitutivas: territorial, administrativa, fiscal, social), emergiram e se instituíram as democracias do tipo ocidental. Entretanto, a pressão dos mercados globalizados solapa a capacidade dos Estados nacionais de influenciar politicamente o mercado econômico, prejudicando visivelmente a autonomia e a capacidade de ação político-econômica dos atores estatais. A regulação transnacional das decisôes opera segundo outra lógica, na qual o dinheiro substitui o poder, o mercado substitui a política. $\mathrm{O}$ desalojamento da política pelo mercado significa a destruição dos pressupostos sociais para uma participação política, o estreitamento da política social, a dissolvência das formas de integração nacionais tradicionais, o esvaziamento programático de uma política que suspende os pontos de vista normativos, em vista da adequação aos imperativos sistêmicos tidos como inevitáveis. Com a perda do controle, o impotente Estado nacional não consegue mais cumprir as exigências de legitimaçáo.

Diante da decomposição dos liames nacionais, despontaram em âmbito regional e global organizaçóes e práticas políticas plurais com o objetivo de compensar, em alguns setores, as brechas de ineficiência, a perda da autonomia e da capacidade de ação do Estado nacional (por exemplo: Fundo Monetário Internacional e Banco Mundial, G7, NAFTA, MERCOSUL, ASEAN e União Europeia, no campo econômico; Organização Mundial da Saúde, Agência Atômica Internacional, agências especiais da Organização das Naçôes Unidas, ou ainda: Organizaçóes Não-Governamentais, como Greenpeace e Anistia Internacional).

Todavia, do ponto de vista político, a consequência mais lesiva é que a transferência de competências nacionais para agências ou organismos que atuam internacionalmente estabelece "vazios de legitimaçáo". Acordos entre atores coletivos que resultam em regulaçóes intergovernamentais carecem de legitimação que deveria derivar de uma sociedade civil e uma esfera pública constituída politicamente. A constelação pós-nacional significa o esvaziamento do poder do Estado nacional, criando um déficit de legitimação, visto que as decisões democráticas estão desacopladas dos destinatários, estão subtraídas das arenas nacionais, os atingidos não participam da "produção" da 
legitimidade (veja-se, por exemplo, o caso da Uniăo Europeia e os processos decisórios burocráticos dos especialistas de Bruxelas).

A consequência política da integração global via imperativos econômicos parece ser a superação do Estado nacional e sua autonomia. $\mathrm{Na}$ era da globalização, o Estado teria perdido por completo sua função, incapaz de agir sobre si mesmo, chegando ao fim também toda forma de sociabilidade política, uma era pós-política. Ressalta Habermas (1996, p. 151):

A autonomia dos cidadãos é prontamente diminuída na proporção do comportamento moral da autodeterminação ligada a cidadania reconhecida pelo Estado e realocada para o fundamento da autonomia privada [...] O Estado democrático é substituído por um Estado de direito privado sem qualquer remissão filosófica ao direito natural, reduzido a um código de regras e legitimado apenas pela comprovação diária da sua capacidade funcional. Em lugar de normas que são efetivas e que também obedecem a pontos de vista como soberania popular e direitos humanos, surge agora - sob a forma de uma "lógica da integraçáo em rede" - a mão invisível de processos regulados de maneira pretensamente espontânea.

A globalização econômica modificou a constelação histórica da relação, dentro das fronteiras nacionais, entre Estado, sociedade e economia, mas modificou especialmente a relação entre mercados e poder político, enfraquecendo o papel dos atores estatais, uma vez que, agora, não é mais o mercado que está inserido na dinâmica estatal nacional, mas são os Estados que estão inseridos no mercado global. Apesar de a dissolução das fronteiras não ser exclusiva da economia, mas se dê também no nível da política (tratados de paz, fluxos migratórios, redes de comunicação, conflitos de identidade cultural...), mesmo assim, essa diluição se processa mais aceleradamente no campo da economia (do que na política) e acaba atingindo, fatalmente, a dinâmica política nacional, ameaçando o Estado social bem como a afinidade entre democracia e Estado nacional, cujo projeto havia conseguido compensar, no nível nacional, os efeitos indesejados do capitalismo. Se, por um lado, o Estado nacional havia conseguido produzir uma forma abstrata de solidariedade entre estranhos e o Estado social havia conseguido atender às exigências políticodemocráticas das sociedades nacionais, por outro lado, a globalização elimina essa afinidade, esse entrelaçamento entre Estado, sociedade e economia, ameaçando o fundamento pré-político da integração dos cidadãos.

A expulsão da política pelo mercado implica a diminuição da eficácia interventiva e reguladora do Estado nacional em termos de política social. $\mathrm{O}$ 
Estado nacional enfrenta o dilema de, por um lado, ter que oferecer condiçóes apropriadas para os investimentos e lucros do capital (mesmo com o perigo de mobilidade e fuga do capital, com o aumento de impostos) e, por outro, ter que compensar a ameaça aos padróes sociais, o crescente potencial de desemprego e a sobrecarga do sistema de seguridade social. Ou seja, precisa diminuir a carga tributária/cobrança de impostos e, ao mesmo tempo, aumentar o sistema de seguridade social. Este é o paradoxo que leva a capacidade assistencialista do "Estado social" ao seu limite: fomentar o desenvolvimento econômico excludente e, ao mesmo tempo, dar conta da exclusão que o mesmo ajuda a fomentar. ${ }^{6}$

e) Soberania social. Como a globalização influencia o nexo entre Estado nacional e Estado social? Impacto social. O fim do compromisso com o Estado social. Privatizaçóes e desmonte do Estado social.

A globalização implica uma política econômica de desregulação dos mercados, cuja sequela imediata é a desconstrução do Estado social, em forma de custos sociais e políticos da desintegração social, dissolução da solidariedade, com base nos indicadores do aumento da pobreza e de insegurança social que desafiam a estabilidade democrática da sociedade. A globalização "destrói uma constelação histórica que havia provisoriamente permitido o compromisso do Estado social". Sob as condiçóes da economia globalizada, o controle da dinâmica econômica, a partir de um Estado intervencionista, deixa de ter êxito. Escreve Habermas (1998, p. 84):

Em algumas regiôes privilegiadas e sob condiçóes propícias do pós-guerra, o Estado nacional [...] pode se transformar em Estado social - graças à regulação de uma economia política, no entanto, intocável no seu mecanismo de autocontrole. Essa combinação bem-sucedida está ameaçada na medida em que uma economia globalizada foge às intervençóes desse Estado regulador. As funçóes do Estado social evidentemente só poderão continuar a ser preenchidas no mesmo nível de até agora se passarem do Estado nacional para organismos políticos que assumam de algum modo uma economia transnacionalizada.

A globalização econômica tem ainda outra influência decisiva na política social estatal, perceptível na redução de investimentos sociais e no maior rigor no acesso ao sistema de seguridade social (previdência social). Um

${ }^{6}$ Habermas já havia sinalizado esse paradoxo em Habermas (1973, 2003). 
dos resultados dessa cisão entre Estados nacionais e imperativos econômicos globais é o problema do desemprego também agora em países desenvolvidos. Já se delineiam, mesmo nos países desenvolvidos, condições de vida precarizadas, configurando-se uma nova "subclasse": grupos marginalizados que não têm mais como alterar sua condição de vida por si mesmos. Nesse caso, tensôes sociais autodestrutivas e o incremento na construção de penitenciárias são apenas algumas das consequências sociais e políticas que decorrem da erosão dos laços de solidariedade, da desolação social, da miserabilização física e da erosão moral cívica.

Dentre os principais efeitos colaterais da globalização econômica e a desregulação dos mercados, notabiliza-se o aumento da desigualdade social, mesmo em países desenvolvidos: o aumento constante do número de desempregados, do número de pessoas que recebem auxílio social ou que simplesmente vivem abaixo da linha da pobreza, o qual chega à casa dos milhôes, apesar do aumento dos lucros e das açóes nas Bolsas de Valores. É nesse sentido a crítica de Habermas (1998, p. 78-79) ao capitalismo neoliberal e ao fim do compromisso do Estado social:

$\mathrm{Na}$ figura da democracia de massa de Estados sociais, a forma econômica altamente produtiva do capitalismo foi sujeitada pela primeira vez de modo social e mais ou menos harmonizada com a autocompreensáo normativa de Estados constitucionais democráticos [...]. O final do século (livro escrito em 1998, NA) encontra-se sob o signo do risco estrutural de um capitalismo domesticado de modo social e do renascimento de um neoliberalismo indiferente ao social [...]. A globalização econômica constitui o principal desafio para a ordem social e política nascida na Europa pós-guerra.

Além desses, outros problemas e conflitos sociais desafiam os fundamentos democráticos dos Estados de bem-estar social e colocam em xeque a capacidade política de uma sociedade que atua sobre si mesma, de forma democrática, dissolvendo a capacidade de ação necessária para interferir e transformar a dinâmica em curso. $O$ declínio do Estado social torna-se o maior desafio político de uma constelação pós-nacional para o futuro da democracia, porque afeta as condiçóes de legitimidade e de funcionamento das democracias do Estado nacional. 
f) Soberania trabalhista. Como a globalização influencia o nexo entre Estado nacional e mercado de trabalho (justiça social)? Impacto trabalhista.

A desregulação dos mercados econômicos e a competição mundial alteram significativamente as condiçóes de funcionamento do mundo do trabalho. Nesse sentido, a discussão sobre justiça social e eficiência de mercado entra em uma nova fase, com a unificação econômica europeia. Uma vez que o Estado nacional náo consegue dar conta da desnacionalização da economia, as discussóes sobre emprego e trabalho assalariado se dissipam, enquanto fim político, e aceleram a dinâmica do empobrecimento e de marginalização social; veja-se o diagnóstico nada animador dos índices de desemprego na casa dos milhôes, tanto na União Europeia quanto em países como Inglaterra e Estados Unidos (HABERMAS, 1998). Abrir mão do objetivo político do pleno emprego pode significar a diminuição dos padrôes de justiça social e solidariedade coletiva. Mesmo em países abastados da América do Norte e Europa, as políticas sociais dos Estados nacionais mostram-se insuficientes no combate à decadência do padrão social, consequência de mercados de trabalho globalizados e em rápida expansão. Se há pouco ainda se pensava em políticas de renda mínima articuladas pelo Estado nacional como viabilidade de reforma social, hoje o cenário possível de respostas poderia dar-se apenas se articulado num nível pós-nacional.

\section{COMO REEQUilibrar POLÍtica E MERCADO? É POSSÍVEL REENQUADRAR POLITICAMENTE OS MERCADOS? DESAFIOS DA DEMOCRACIA NA CONSTELAÇÁO PÓS- NACIONAL}

Será que a perda da influência da politica em nivel nacional aponta na direção de uma abdicação da política em geral ou será que o medium da política pode se regenerar noutros niveis e crescer na esteira dos mercados transnacionais? (HABERMAS, 2001, p. 14)

Apesar do impacto da globalização econômica do capitalismo neoliberal esvaziando a soberania cultural, econômica, administrativa, jurídica dos Estados nacionais, aqui interessam os impactos políticos e sociais da globalização: as consequências do esvaziamento da soberania política dos Estados nacionais, 
o esfacelamento do nexo original entre Estado nacional e democracia, o desmonte do Estado social, o desalojamento/expulsão da política pelo mercado e o futuro da democracia na constelação pós-nacional.

\section{a) Crítica ao modelo neoliberal de sociedade de mercado desestatizada}

O neoliberalismo se orienta pela lógica do Estado social mínimo e pela eficiência do mercado que, por sua própria dinâmica, haveria de garantir uma divisão socialmente justa. No entanto, a alternativa neoliberal, com sua desregulamentação de mercados e privatização dos serviços básicos, não encontra, para Habermas (1998, p. 141) "[...] uma justificativa funcional [...] para tornar aceitável de modo normativo diferenças sociais muito gritantes". Esta é a crítica: a opção do neoliberalismo pela desregulamentação dos mercados, em detrimento de questóes de justiça social, demonstra o grau de insensibilidade em relação aos custos sociais: "Os mercados são surdos para informaçôes cuja linguagem não seja a dos preços", frisa Habermas (1998, p. 143). Além disso, por reproduzir vantagens já estabelecidas, fracassa também a "força igualizante" do mercado, uma vez que não satisfaz as exigências ideais de livre competição. Segundo a crítica de Habermas (1998, p. 239) ao neoliberalismo, estamos sucumbindo às pressóes e nos adequando aos imperativos funcionais:

Não se sabe mais bem ao certo se a concepção democrática de uma sociedade que atua politicamente sobre si com a vontade e a consciência dos seus cidadãos reunidos assume os traços de uma utopia desejável e fora de moda ou de uma utopia perigosa. O neoliberalismo - aliado a uma antropologia pessimista - também nos habitua cada dia mais a uma nova condição mundial na qual a desigualdade social e a exclusão voltam a valer como fatos naturais.

Essa é a crítica ao projeto neoliberal de globalização econômica, para fugir à regulação estatal nacional, ao desenho neoliberal de uma sociedade de mercado desestatizada, a qual marginaliza o Estado e a política, desestatizando a política:

A imagem de uma sociedade de mercado mundial não se ajusta mais a um palco mundial no qual o terrorismo mundial se apresenta e o fundamentalismo religioso reaviva categorias políticas esquecidas [...] $\mathrm{O}$ Belo mundo novo dos neoliberais não foi apenas empiricamente destituído de valor; do ponto de vista normativo, era fraco desde o 
início. Rouba do indivíduo a sua autonomia de cidadáo de Estado e o abandona às contingências de eventos de uma complexidade incontrolável. As liberdades subjetivas do sujeito privado são apenas os fios dos quais o cidadão autônomo da sociedade bamboleia como uma marionete (HABERMAS, 2004, p. 185-186).

Também no apêndice da obra Zur Verfassung Europa [Sobre a Constituição da Europa] (2011), ao escrever sobre a crise de legitimação do capitalismo globalizado, Habermas faz uma crítica enérgica ao Consenso de Washington e seu famigerado projeto econômico com o qual os países deveriam ser reformados:

Tornou-se digna de escárnio a agenda que concede aos interesses dos investidores um predomínio sem escrúpulos, que aceita passivamente a desigualdade social crescente, o surgimento de um "precariado", a pobreza infantil, os salários aviltantes e assim por diante, que solapa, com sua loucura de privatizar, as funçóes centrais do Estado, que retalha os restos da deliberação da esfera pública política para facilitar a ampliação dos rendimentos dos investidores financeiros. [...] Desde muitos anos se acumulam provas empíricas de que esse prognóstico ("Deixe os ricos enriquecerem que a riqueza goteja para os pobres”) é falso. Os efeitos do aumento de riqueza são tão assimétricos nacional e mundialmente que as zonas de pobreza se alargam aos olhos de todos nós (HABERMAS, 2011, p. 101-103).

Diante do diagnóstico habermasiano dos impactos da globalização sobre os Estados nacionais, quais as possibilidades de contraposiçáo a essa conjuntura? Quais as chances dos Estados nacionais de compensar a perda das competências? Qual a margem de manobra que ainda resta aos Estados nacionais? Estấo as democracias nacionais subordinadas a uma globalização econômica incontrolável? É possível um controle de mercados globalizados via regulação política? De que modo seria possível domesticar politicamente o capitalismo global desenfreado? Qual poderia ser a resposta política alternativa e apropriada para processos democráticos, para além do Estado nacional? A perda da capacidade de controle político, em nível nacional, pode ser compensada em nível transnacional? A política deveria esforçar-se em alcançar o mercado que parece lhe escapar? A política conseguirá alcançar os mercados? Existe no plano transnacional algum equivalente para o déficit democrático que surge no plano nacional? As comunidades políticas podem formar uma identidade coletiva, para além das fronteiras de uma nação e, desse modo, 
preencher as condiçôes de legitimação para uma democracia pós-nacional? Qual a possibilidade de uma política transnacional? Quais as chances de estender a forma de influência democrática das sociedades sobre si mesmas, articulada nos Estados nacionais, num contexto pós-nacional? Enfim, trata-se de saber se é possível ou não desenvolver uma democracia social-estatal, para além das fronteiras nacionais.

Embora, no último quartel do século passado, o Estado social tenha conseguido compensar os efeitos indesejados de um sistema econômico altamente produtivo, nas sociedades desenvolvidas - o conceito de uma sociedade que influi sobre si mesma, através dos meios políticos -, com a globalização econômica, esse projeto atinge seus limites. O temor de Habermas é que náo se consiga, mesmo nas sociedades desenvolvidas, enquadrar politicamente os mercados, sobrecarregando e enfraquecendo ainda mais os Estados nacionais. Sobre esse ceticismo, escreve Habermas (2001, p. 85): “Os mercados só reagem a mensagens codificadas na linguagem dos preços. Isso significa que eles são surdos em relação aos efeitos externos que eles mesmos geram em outras esferas".

b) Respostas políticas: os desafios da democracia diante da globalização (HABERMAS, 2001, p. 92-98).

Segundo Habermas, ao menos quatro são as respostas políticas que se apresentam, diante dos desafios da globalização:

- Neoliberais: os que são simplesmente a favor da globalização e da desterritorializaçâo. Recomendam a subordinação do Estado aos imperativos de uma integração socioeconômica transnacional (des)regulada pelos mercados, restando-lhe a tarefa de Estado empreendedor, preparando a infraestrutura e os cidadãos para o trabalho empresarial; defendem a diminuiçáo do Estado social.

A primeira objeção de Habermas é que o período de transição fatalmente levaria ao crescimento da injustiça social e da fragmentaçáo da sociedade, e à corrupção dos padróes morais e das infraestruturas culturais. Mesmo que a desregulação econômica dos mercados globais realize o equilíbrio global de uma divisão do trabalho simétrica, é preciso considerar os custos de um período de transição capaz de provocar um crescimento acentuado 
das injustiças sociais e do esvaziamento das funções e dos espaços de ação do Estado nacional.

A segunda objeção de Habermas denuncia o esvaziamento da democracia, o qual implicaria, por conseguinte, a fragmentação do tecido social e cultural, sob o qual se erigiram arranjos democráticos que conferem aos cidadãos possibilidades de influência política em suas condiçóes sociais, mas para os quais não se avistam equivalentes em nível supranacional. É nesse sentido que a globalização econômica provocaria uma nova "mudança estrutural da esfera pública", a partir da mudança do deslocamento de peso nas relaçóes entre Estado, sociedade e economia, com ênfase agora no mercado, e não mais no Estado; trata-se de uma nova "despolitização", não provocada pelo Estado intervencionista/ regulador (como nas décadas de 70 e 80), contudo, pela desregulação do Estado acentuadamente de viés econômico; consequência do esvaziamento do âmbito político.

- Protecionistas: os que são simplesmente contra a globalização. Contra a erosão da afinidade entre Estado nacional e democracia, o esvaziamento do poder democrático do Estado e a decadência social, defendem a necessidade de fechar as comportas contra tudo que possa transcender as fronteiras nacionais (traficantes de armas e drogas que colocam em risco a segurança nacional; filmes estrangeiros, os quais póem em risco a cultura nacional; capital estrangeiro; imigrantes, que colocam em risco o padrão de vida local).

A objeção de Habermas é quanto à rejeição etnocêntrica e xenofóbica; a globalização econômica é um fato, e é inócua a tentativa de fechar o Estado nacional sobre si mesmo, com o objetivo de recuperar sua antiga força. Numa era globalizada, qualquer reação protecionista baseada no fechamento do Estado está condenada ao derrotismo. Não existe nenhuma perspectiva para projetos restauradores que pretendem abandonar unilateralmente o resultado sistêmico da globalização econômica além-fronteiras.

Todavia, diante das limitações da esfera de atuação dos Estados nacionais, estas duas alternativas que se apresentam - abertura e fechamento não conduziriam muito longe. Enquanto a primeira posição, mais ofensiva e libertária, saúda o capitular das fronteiras territoriais e sociais como libertaçáo dos indivíduos da regulação estatal e das pressóes assimiladoras de um comportamento coletivo, a segunda posição, mais defensiva e de recusa, apela para o caráter protecionista do Estado, capaz de monopolizar a violência, o 
direito, a ordem, a segurança interna, os imigrantes e o capital estrangeiro. Entretanto, para Habermas, ambas as posiçōes são superficiais e é preciso tomar cautela, tanto em relação aos projetos de abertura que se apresentam como progressivos quanto em relação às utopias regressivas de fechamento:

Sob as condiçóes cambiantes da constelação pós-nacional, o Estado nacional não pode recuperar sua força anterior com base em uma política de fechamento (Politik des Einigelns; sich zurückziehen). O protecionismo neonacional náo pode explicar como uma sociedade mundial poderia ser novamente dividida em seus segmentos [...]. Igualmente pouco convincente é uma política de autoliquidação que permita que o Estado se desfaça das redes pós-nacionais. $\mathrm{O}$ neoliberalismo pós-moderno não pode explicar como os déficits de controle e de legitimação, surgidos em termos nacionais, poderão ser equilibrados em um nível supranacional sem novas formas de regulamentação nomeadamente políticas [...]. Tal projeto dirige aos atores do Estado nacional a expectativa paradoxal de perseguir hoje, já nos limites de suas atuais capacidades de ação, um programa que só podem evidentemente realizar para além desses mesmos limites (HABERMAS, 1998, p. 124-125).

Aqui aparece mais claramente o paralelo estabelecido por Habermas entre neoliberalismo e pós-modernismo, pois ambos convergem para o fim $\mathrm{da}$ política. Para as teorias pós-modernas, não faz sentido um novo fechamento do ponto de vista político, porque a capacidade de autolegislaçáo e integraçáo social da coletividade se decompóem no rastro da derrocada do Estado nacional. Escreve Habermas (1998, p. 133-134):

Junto com a forma de organização do Estado nacional deve perder também a sua base uma política de bem-estar social que supostamente atrofiou-se em uma mera "administração do social" [...]. Para o pós-modernismo, a dissoluçáo das sociedades organizadas com base no Estado nacional implica o "fim da política", no qual também o neoliberalismo (que quer passar tanto quanto possível para a funçáo de controle do mercado) deposita suas esperanças [...] Partindo de premissas diferentes, pós-modernismo e neoliberalismo concordam com a mesma visấo: os mundos da vida dos indivíduos e de pequenos grupos se dispersam como mônadas por redes que se estendem pelo mundo e são coordenadas funcionalmente, em vez de se engrenarem nos caminhos da integração social em unidades políticas maiores e mais estratificadas.

Contudo, ao considerar que nem os favoráveis nem os opositores da globalização mercantil oferecem argumentos conclusivos, em contrapartida, 
Habermas vislumbra no horizonte uma terceira via, a qual se bifurca em duas: defensiva e ofensiva.

- Defensiva: para a terceira via, em sua variante defensiva, a subordinação da política aos mercados se tornou inevitável (o capitalismo não pode ser mais domesticado) e, por isso, aposta na força estruturante de uma política que, no plano supranacional, tenta alcançar os mercados que fugiram do controle nacional (no máximo, o capitalismo pode ser amenizado, em termos nacionais). Em vez de reativo, o Estado deve assumir um papel ativo e desenvolver uma política social que capacite seus cidadãos para a concorrência (o Estado proteger o trabalhador dos riscos da desregulamentação dos mercados econômicos e das relaçôes trabalhistas), qualificá-los com habilidades empresariais (capacitá-lo com qualidades empreendedoras), dotá-los de capacidade e eficiência necessária para concorrer no mercado (ajudar a inseri-lo da melhor forma no mercado competitivo). Trata-se de um deslocamento do ônus da responsabilidade e dos riscos do Estado para o cidadão; colocando o risco em suas costas, o indivíduo não precisa recorrer ao amparo social do Estado.

A primeira objeção de Habermas é que o critério de igualdade social seria entendido apenas como igualdade de oportunidades. Abandonar o objetivo político do pleno emprego significa abrir mão dos padrôes públicos de justiça social. Ao considerar que o trabalho remunerado informal continua sendo a chave da integração social, os partidários dessa "terceira via defensiva" (Habermas (2001, p. 96) denomina "nova esquerda") se alinham com o imaginário ético do neoliberalismo: uma forma de vida ética orientada pelo mercado mundial.

A segunda objeção de Habermas é que a noção de "homem flexível" seria apenas uma justificativa para sobrecarregar o indivíduo com o peso dos problemas que ela mesma (a integração social neoliberal) não consegue resolver.

- Ofensiva: a terceira via, em sua variante ofensiva, orienta-se, não pela lógica do mercado, mas sim pela prioridade da política, criando condiçóes políticas para além do Estado nacional. A política, vinculada a um processo democrático de legitimaçáo apoiada no princípio do discurso, poderia opor-se aos mercados globalizados. Embora não possa ser mais operada no quadro do Estado nacional, em virtude da desconstrução da democracia nacional e da impossibilidade de sua reconstruçáo, uma política deliberativa poderia ajudar a delimitar as fronteiras da lógica sistêmica do mercado, no âmbito de unidades 
políticas maiores, além das fronteiras nacionais, compensando a perda de função do Estado nacional, sem que o elo de legitimação fosse cortado. ${ }^{7}$ No entanto, diante dos mercados globais, a política só poderá se estender, quando criar uma infraestrutura capaz de sustentar uma política interna voltada para além-fronteiras.

Não se trata, todavia, de uma política recuperada capaz de competir pelo poder entre atores políticos e econômicos nacionais envolvidos, porém, de organizar uma política capaz de inverter o processo segundo o qual a produçáo democrática do poder político, a qual depende de processos comunicativos que autorizam o uso do poder, deve orientar - Habermas (2001, p. 97) usa o termo "reprimir" - a dinâmica econômica num nível ampliado transnacional. Para Habermas, essa via seria mais convincente, porque náo sacrificaria as vítimas da globalização, nem interromperia a corrente de legitimação democrática iniciada no âmbito dos Estados nacionais.

\section{c) Desafio histórico análogo: impulso abstrato para uma cultura politica pós- nacional.}

Diante dos desafios da globalizaçáo econômica, Habermas argumenta em favor de novas formas de autocondução democrática, agora no contexto da constelação pós-nacional. O mercado se desgarrou do controle/regulação dos Estados nacionais e opera, de forma predominante, na esfera transnacional. Em contrapartida, apenas seria possível reequilibrar mercado e política, estendendo também as formas de condução política nacionais para a esfera transnacional; somente a extensão da democracia estatal-social para além das fronteiras nacionais (democracia pós-nacional) seria capaz de resolver o desequilíbrio entre política e mercado, o déficit de coordenação política, a lacuna de socialização (integração social), no plano transnacional.

Embora seja cada vez mais difícil a política acompanhar a concorrência dos mercados globalizados, torna-se necessário uma maior afinidade entre a política econômica e social (uma vez que o neoliberalismo defende um Estado social e político mínimo), uma política social e econômica direcionada para o futuro de uma ordem cosmopolita socialmente mais equilibrada. É nesse sentido que aponta a exigência habermasiana da reconstrução do Estado social

\footnotetext{
7 Nesse sentido, naquela época, a União Europeia se apresentava como o primeiro exemplo para uma democracia para além dos limites dos Estados nacionais. Sobre os problemas da democracia transnacional na União Europeia, ver: LUBENOW, 2015, 2016, 2017.
} 
num plano supranacional, porque essas instituiçóes supranacionais ainda não existem. Nesse sentido, Habermas (1996, p. 150) ainda procura tratar o tema de forma menos derrotista, não do ponto de vista da "supressão" (Abschaffung), superação, extinção do Estado nacional, mas, antes, da sua "suprassunção" (Aufhebung), suspensão, atuação diminuída.

O ponto de partida de Habermas (1996, p. 154) é a crítica à visão "substancialista" e a recomendação de uma compreensão "procedimentalista" de soberania popular; uma leitura menos etnonacionalista e mais republicana dos conceitos de nação, Estado de direito e democracia. Essa compreensão procedimentalista conduziria a conceitos diferentes de autodeterminação nacional, de multiculturalismo e soberania do Estado. Trata-se de uma "cultura política pós-nacional” acima das subculturas nacionais, de procedimentos e instituições democráticas pós-nacionais. Conforme o filósofo alemão, seria preciso situar o nível de integração social e política num nível ainda mais abstrato, o da compreensão pós-nacional da coletividade.

Nesse sentido, Habermas recomenda o que me parece a sua tese central em torno da discussão sobre a formação política pós-nacional: usar o mesmo recurso abstrato de formação de uma "consciência nacional", na formação dos Estados nacionais, para a formação de uma "consciência pós-nacional”. Dar um salto de abstração do nacional para o pós-nacional. É um desafio análogo ao da formação dos Estados nacionais. O exemplo seria o da União Europeia e seus problemas, na tentativa de passar da união monetária para uma união política. A Europa se encontraria, agora, diante de um problema estrutural semelhante ao que deu origem aos Estados nacionais (a necessidade de unificação política da nação): a unidade política (nacional), que antes era organizada nos Estados nacionais, a partir da ideia abstrata de "nação", em sua versão nacional-popular, agora deve ser organizada no nível europeu, com base na ideia abstrata de uma comunidade de "cidadãos", de relaçôes comunicativas que ultrapassem as esferas públicas nacionais. Escreve Habermas (1998, p. 36):

A moldura nacional-estatal para a implementação dos direitos humanos e da democracia tornou possível uma nova forma mais abstrata de integração social para além das fronteiras das linhagens e dialetos. Hoje nos encontramos diante da tarefa de dar continuidade a esse processo com mais um passo em direção à abstração. Uma formação da vontade democrática que ultrapasse as fronteiras necessita de um contexto apropriado. Para tanto, deve-se desenvolver uma esfera pública política de dimensóes europeias e uma cultura política comum. 
Ainda se referindo à União Europeia, Habermas diagnostica o anacronismo da soberania externa dos Estados, em face das coaçóes e imperativos subversivos do mercado e do incremento global das comunicaçóes e dos transportes, e a ausência de atores coletivos capazes de criar instituiçóes políticas eficientes, num nível pós-nacional. A consequência mais perigosa seria uma lacuna de legitimação, resultado da organização de associaçóes e instituiçóes afastadas das bases (por exemplo, a burocracia de Bruxelas), aumentando o fosso entre as administraçóes burocráticas e os processos genuinamente democráticos. Em contrapartida, esse problema de legitimação poderia ser resolvido superando-se a visão étnica da identidade dos Estados, não no sentido de um "povo europeu homogêneo", mas no sentido de uma "compreensão política-cultural europeia". Seria preciso olhar para o que, de fato, une os povos europeus, ter no horizonte a necessidade de superar as compreensões nacionalistas de exclusão, e reconhecer e construir laços de solidariedade comuns, mediados juridicamente. Para tanto, as noçóes de esfera pública política e sociedade civil adquirem um papel relevante. Assinala Habermas (1996, p. 184):

O próximo impulso no sentido da integração numa socialização pósnacional não depende do substrato de algum "povo europeu", mas de redes de comunicaçáo de uma opiniáo pública política de alcance europeu, enfronhada numa cultura política comum, sustentada por uma sociedade civil com associaçóes de interesses, organizaçôes não-governamentais, iniciativas e movimentos cívicos, e que seja assumida pelas arenas nas quais os partidos políticos possam se referir imediatamente às decisóes das instituiçôes europeias, para além das alianças de bancadas, até chegarem a ser um sistema partidário europeu.

Diante disso, Habermas retoma, como recurso argumentativo, o que uma vez já foi um dos pontos fortes do Estado nacional: a capacidade de fechar brechas de legitimação e integração social, com base na participaçáo política de seus cidadáos. Nesse caso, em contrapartida, o processo democrático poderia assumir, agora num âmbito ampliado, uma garantia para a coesão e justiça social de uma sociedade diferenciada cultural e funcionalmente. Escreve Habermas (1998, p. 117):

Em sociedades complexas, a formação da vontade e da opiniáo deliberativa dos cidadáos - fundada no princípio da soberania do povo e nos direitos do homem - constitui em última instância o meio para uma forma de solidariedade abstrata, criada de modo geral e reproduzida graças à participaçáo política. O processo democrático [...] só pode afastar o perigo 
de uma perda de solidariedade à medida que corresponder a critérios reconhecidos de justiça social.

No entanto, saber se a formação democrática da opinião e vontade será capaz de criar vínculos efetivos pós-nacionais equivalentes ainda é uma questão em aberto. De todo modo, ela não poderá se dar, sem a organização de uma sociedade civil e de uma esfera pública política pós-nacional:

Uma ordem mundial e uma ordem econômica global mais pacífica e mais justa não podem ser concebidas sem instituiçóes internacionais capazes de agir, nem sem processos de conciliação entre os regimes continentais ora emergentes, nem tampouco sem políticas que provavelmente só poderão se impor sob a pressão de uma sociedade civil capaz de transitar em esfera global (HABERMAS, 1996, p. 153).

Como vemos, Habermas desloca esse (novo) fiador da integração social nas sociedades pluralistas para além das raízes e fundamentos nacionalistas, para o nível das instituiçóes e dos procedimentos democráticos, não baseados na substantiva "origem natural ou cultural", mas no "substrato procedimental" de formação da vontade política e comunicação pública, capaz de estabelecer uma solidariedade cidadã e vínculos normativos entre estranhos. Destaca Habermas (1996, p. 164):

A ideia de uma soberania popular de tal modo procedimentalizada e orientada para o futuro faz com que perca sentido a reivindicaçáo de retornar a formaçáo de uma vontade política ao a priori substantivo de um consenso passado obtido entre membros de um povo homogeneizado num momento pré-político [...]. Não é necessário um consenso básico anterior, garantido pela homogeneidade cultural, porque uma formação democraticamente estruturada de opinião e de vontade política possibilita um acordo normativo racional também entre estranhos. Pelo fato de o processo democrático, graças às suas características procedimentais, garantir legitimidade, ele pode, quando necessário, preencher as lacunas da integração social.

Este seria o cerne da concepção intersubjetiva da soberania popular procedimentalizada de Habermas, segundo o qual o modelo de integração social baseado no contrato social do direito privado entre participantes seria substituído por um processo de comunicação pública: 
A formação da opinião e da vontade políticas não se realiza apenas na forma de compromissos, mas também segundo o modelo dos discursos públicos, que visam aceitabilidade racional das regras, à luz de interesses generalizados, de orientaçóes de valor compartilhadas e de princípios fundamentados. Desse modo, esse conceito não-instrumental de política apoia-se no conceito de pessoa que age comunicativamente [...]. Esse processo se qualifica muito bem para a tarefa de assumir o papel de fiador político em caso de inadimplência das funçôes de integração (HABERMAS, 1996, p. 165-166).

Essa compreensão procedimental da autodeterminação democrática (soberania popular), que visa a incluir uniformemente todos os cidadáos num processo de autolegislaçáo, teria maior afinidade com o republicanismo e, ao lidar segundo os princípios da teoria da ação comunicativa, seria mais apropriada do que a leitura etnonacionalista dos conceitos de naçáo, Estado de direito e democracia. Escreve Habermas (1996, p. 166-167):

Avisão substancialistadasoberania popular refere "liberdade" essencialmente à independência externa de um povo; visão procedimentalista, por sua, vez, refere-se à autonomia privada e pública, uniformemente garantida internamente a uma associação de jurisconsortes livres e iguais.

Em face do déficit de coordenação política, no âmbito mundial, Habermas (2011, p. 104-105) argumenta pela necessidade de equilibrar mercado e política, capitalismo e democracia:

A globalização econômica, politicamente desejada, deveria ter sido seguida por uma coordenaçáo política mundial e por uma juridificação mais ampla das relaçóes internacionais... A presente crise nos faz tomar consciência desse déficit [...]. Desde o começo da Modernidade, mercado e política têm de ser balanceados continuamente, de modo que a rede de relaçóes solidárias entre os membros de uma comunidade política não se despedace. Uma tensão entre capitalismo e democracia permanece sempre, visto que mercado e política baseiam-se em princípios opostos. Também, após a última onda de globalização, o fluxo de decisóes seletivas, descentralizadas e liberadas, formando redes cada vez mais complexas, requer regulamentaçôes que não podem existir sem uma ampliaçáo correspondente de procedimentos políticos de universalização de interesses.

Entretanto, embora seja possível observar indicadores de uma "política interna mundial" - governos europeus e asiáticos têm propostas 
de regulamentação dos mercados financeiros, de obrigaçóes com a balança comercial, de responsabilidade pessoal de executivos, de controle sobre as bolsas de valores, e até imposto sobre movimentação financeira-, o estabelecimento dessa nova arquitetura do sistema financeiro esbarra nas objeçóes provenientes dos Estados Unidos e sua política internacional unilateral (HABERMAS, 2011, 2013; LUBENOW, 2018, 2019).

\section{ConsideraçốES FINAIS}

O artigo apresentou o diagnóstico crítico dos impactos da globalização econômica sobre os Estados nacionais e a contrapartida crítica de Jürgen Habermas, para resolver especialmente os impasses políticos e sociais, a partir de uma nova compreensão do processo político democrático, para além dos Estados nacionais.

A expansão econômica globalizada modifica a relação entre economia transnacional e Estados nacionais, delineando mecanismos de funcionamento de fogem ao controle estatal. Culturalmente, impacta a relação entre Estado nacional e identidade cultural coletiva nacional, fragmentando o substrato cultural e a solidariedade cívica de um povo/naçáo, antes fiadora da integração social, e diferenciando em multiplicidade das formas culturais de vida. Economicamente, impacta o nexo entre Estado nacional e economia, alterando a anterior relação recíproca entre Estado e economia para uma agora crescente desnacionalização da produção econômica e consequente desregulação dos mercados, perdendo a política, de modo progressivo, a capacidade de influenciar as relaçôes produtivas e tributação; não é mais o mercado que está inserido na dinâmica estatal nacional, mas são os Estados que estáo inseridos no mercado global. Administrativa e juridicamente, impacta o nexo entre Estado nacional e efetividade administrativa reguladora e segurança jurídica, pelas ameaças que extrapolam fronteiras nacionais (ecológicas, criminalidade, tráfico de drogas e armas, epidemias, segurança tecnológica, mobilidade de capitais, entre outros). Politicamente, impacta o nexo entre Estado nacional e democracia, desalojando a política pelo mercado, uma lógica na qual o dinheiro substitui o poder, o mercado substitui a política; isso afeta o funcionamento das democracias nacionais, através da dissolvência das formas de integração nacionais tradicionais e do esvaziamento programático de uma política que suspende os pontos de vista normativos, em vista da adequação aos imperativos sistêmicos tidos como inevitáveis, criando vazios de legitimação; a consequência política da integração 
global via imperativos econômicos parece ser a superação do Estado nacional e sua autonomia. Socialmente, impacta o nexo entre Estado nacional e Estado social (justiça social), destruindo o Estado de bem-estar social e privatizando serviços essenciais do Estado, perceptível na redução de investimentos sociais, no maior rigor no acesso ao sistema de seguridade social (previdência social), no aumento da pobreza (nas condiçôes de vida precarizadas, mesmo em países desenvolvidos, no aumento constante do número de desempregados, no número de pessoas que recebem auxílio social ou que simplesmente vivem abaixo da linha da pobreza) e insegurança social (na erosão dos laços de solidariedade, na desolação social, na miserabilização física e da erosão moral cívica); privatiza funções centrais do Estado para facilitar a ampliação de rendimentos de investidores financeiros.

No mercado de trabalho, impacta o nexo entre Estado nacional e mercado de trabalho, através da desregulação dos mercados econômicos, competição mundial, desnacionalização da economia, afetando profundamente o mercado de trabalho, emprego e trabalho assalariado, os quais se dissipam enquanto fim político e aceleram a dinâmica de decadência do padrão social pelo empobrecimento e de marginalização social, mesmo em países desenvolvidos dos da América do Norte e Europa. Trata-se de um modelo de sociedade de mercado desestatizada que se orienta pela lógica do Estado social mínimo e pela eficiência do mercado, contudo, que não encontra uma justificativa funcional para aceitar de modo normativo desigualdades tấo gritantes, em que a exclusão e a desigualdade social passam a valer como fatos naturais.

Em face do problema, qual a resposta política alternativa capaz de domesticar politicamente os mercados globalizados, equilibrando democracia e capitalismo? Quais as chances de reconstruir a democracia Estatal-social para além das fronteiras nacionais, de estender o compromisso do Estado social para instituiçóes e procedimentos, no âmbito transnacional? Eis o principal desafio da democracia, na constelação pós-nacional.

Dentre as respostas políticas que se apresentam, seriam inviáveis: a continuidade da abertura (resposta neoliberal), pela privatização do Estado e o esvaziamento da democracia; a utopia regressiva do fechamento (resposta protecionista), pela rejeição etnocêntrica e xenofóbica; a terceira via ou defensiva (resposta nova esquerda), por se alinhar ao imaginário ético do neoliberalismo ao abandonar o objetivo político do pleno emprego e abrindo mão de padróes públicos de justiça social. 
Em contrapartida, Habermas sugere uma quarta resposta, ofensiva, que se orientaria, não pela lógica do mercado, mas pela prioridade da política, criando condiçóes políticas para além do Estado nacional, ao delimitar as fronteiras da lógica sistêmica do mercado, no âmbito de unidades políticas maiores, ao organizar uma política capaz de inverter o processo segundo o qual a produção democrática do poder político deve orientar a dinâmica econômica, num nível ampliado transnacional. Apenas seria possível reequilibrar mercado e política, estendendo também as formas de conduçáo política nacionais para a esfera transnacional; somente a extensão da democracia estatal-social para além das fronteiras nacionais (democracia pós-nacional) seria capaz de resolver o desequilíbrio entre política e mercado, o déficit de coordenação política, a lacuna de socialização (integração social), no plano transnacional. É preciso uma maior afinidade entre a política econômica e social direcionada para o futuro de uma ordem cosmopolita socialmente mais equilibrada.

Essa via não sacrificaria as vítimas da globalização nem interromperia a corrente de legitimação democrática que se iniciou, no âmbito dos Estados nacionais. Tal desafio histórico seria análogo ao da formação dos Estados nacionais, que exigiu um salto das particularidades locais para a noção de identidade nacional. $\mathrm{O}$ que se exige agora é um salto de abstração para um princípio integrador social e político mais amplo e abstrato de uma identidade política pós-nacional: uma “cultura política pós-nacional”, acima dassubculturas nacionais, de procedimentos e instituiçôes democráticas pós-nacionais, da compreensão pós-nacional da coletividade. Dar um salto de abstração do nacional para o pós-nacional: a formação de uma "consciência nacional" na formação dos Estados nacionais para a formação de uma "consciência pósnacional", náo baseada em raízes ou fundamentos nacionalistas, "origem natural ou cultural", porém, no nível das instituiçóes e dos procedimentos democráticos, no "substrato procedimental" de formação da vontade política e comunicação pública capaz de estabelecer uma solidariedade cidadã e vínculos normativos entre estranhos.

A globalização econômica deve ser acompanhada pela extensão de uma coordenação política e jurídica transnacional. É nesse sentido que aponta a exigência habermasiana da reconstrução do Estado social num plano supranacional, uma vez que essas instituiçóes supranacionais ainda não existem. Um exemplo seria a tentativa da Uniâo Europeia de passar de uma união monetária para uma união política. No entanto, saber se a formação democrática da opinião e vontade será capaz de criar vínculos efetivos pós- 
nacionais equivalentes é ainda uma questão em aberto, como mostram as dificuldades mais recentes da tentativa de integração política da União Europeia, através da elaboração de uma Constituição Europeia, e das objeções provenientes da política internacional unilateral norte-americana, a qual simplesmente ignora o direito internacional.

LUBENOW, J. A. Economic globalization, dismantle of welfare state and transnational political deficit: a critical analysis by Jürgen Habermas. Trans/form/ação, Marília, v. 43, n. 2, p. 99-126, Abr./Jun., 2020.

\begin{abstract}
Aвstract: The article presents Jürgen Habermas critical analysis of the consequences of the neoliberal model of global market integration, in particular the imbalance between politics and market, the end of the commitment to the welfare state and the democratic deficit at the transnational level. For the German philosopher, the neoliberal conception of the privatized society of global capitalism undermine the nexus between national state, democracy and social justice, marginalizing the state and politics in favour of privatization of public services and being insensitive to questions of social justice, the costs increasing poverty, inequality and social exclusion, even in wealthy countries in Europe and North America. Moving the guarantor of social integration across national borders, global capitalism is beyond the state control and exhaust the power of national states in terms of democratic substance and social policy and creates a legitimacy deficit by transferring national powers to agencies or transnational corporations whose legitimacy does not derive from civil society or from a politically constituted public sphere. In contrast, Habermas advocates a democratic power able to politically neutralize the global market, rebuild the welfare-state democracy in a transnational level in view of a more socially balanced order, and compensate the social deficit and democratic legitimacy in the transnational order. After reviewing some problems that have been solved in national state forms, the article describes how economic globalization affects the cultural, economic, administrative, juridical, political, social and labor sovereignty of the national states (1), and what are the possibilities of politically reframing markets, extending welfare-estate democracy beyond national borders (2). In this way, we want to show that Habermas' work is not blind to the relation between democracy and capitalism, to the collateral effects of the "colonization of politics by the economy", to the corrosive influence of the capitalist economy on the depoliticization of the public sphere and politics.
\end{abstract}

KEYwords: Jürgen Habermas. Economic globalization. Transnational democracy. Deficit of legitimation. Welfare state.

\title{
REFERÊNCIAS
}

HABERMAS, Jürgen. Im Sog der Technokratie. Berlin: Suhrkamp, 2013.

HABERMAS, Jürgen. Zur Verfassung Europas: Ein Essay. Berlin: Suhrkamp, 2011.

HABERMAS, Jürgen. Ach Europa. Frankfurt: Suhrkamp, 2008.

HABERMAS, Jürgen. Zwischen Naturalismus und Religion. Frankfurt: Suhrkamp, 2005. 
HABERMAS, Jürgen. Der gespaltene Westen. Frankfurt: Suhrkamp, 2004.

HABERMAS, Jürgen. Zeitdiagnosen: Zwölf Essays. Frankfurt: Suhrkamp, 2003.

HABERMAS, Jürgen. Zeit der Übergänge. Frankfurt: Suhrkamp, 2001.

HABERMAS, Jürgen. Die postnationale Konstellation. Frankfurt: Suhrkamp, 1998.

HABERMAS, Jürgen. Die Einbeziehung des Anderen: Studien zur politischen Theorie. Frankfurt: Suhrkamp, 1996.

HABERMAS, Jürgen. Faktizität und Geltung: Beiträge zur Diskurstheorie des Rechts und des demokratischen Rechtsstaats. Frankfurt: Suhrkamp, 1992.

LUBENOW, Jorge Adriano. A reconstrução habermasiana do projeto kantiano de constitucionalização do direito internacional. Veritas: Revista de Filosofia (PUC-RS), v. 64, n.2, p. 1-41, 2019.

LUBENOW, Jorge Adriano. Democracia e direitos humanos como ideologia: as críticas de Jürgen Habermas à política de poder unilateral norteamericana e à ONU. Aufklärung: Revista de Filosofia, v.5, n.3, p. 141-154, 2018.

LUBENOW, Jorge Adriano. O Ocidente dividido: o impacto da globalização econômica neoliberal na integração política da Uniâo Europeia. Aufklärung: Revista de Filosofia, v.4, n.3, p. 119-134, 2017.

LUBENOW, Jorge Adriano. A redefinição do perfil político da Europa de estatal-social para econômico-liberal: uma análise crítica a partir de Jürgen Habermas. Aufklärung: Revista de Filosofia, v.3, n.2, p. 95-112, 2016.

LUBENOW, Jorge Adriano. The paradox of technocratic democracy and the democratic deficit of European institutions by Jürgen Habermas. Aufklärung: Revista de Filosofia, v.2, n.2, p. 103-122, 2015.

Recebido: 22/6/2018

Aceito: 30/6/2019 